\title{
Article \\ The Effects of the COVID19-Related Lockdown Are Modulated by Age: An Italian Study in Toddlers and Pre-Schoolers
}

\author{
Mariangela Cerasuolo ${ }^{1, \dagger}{ }^{,}$, Serena Malloggi ${ }^{2, *,+} \oplus$, Francesca Conte ${ }^{1}\left(\mathbb{D}\right.$, Benedetta Albinni ${ }^{1}$, Oreste De Rosa ${ }^{1}(\mathbb{D}$, \\ Marissa Lynn Rescott ${ }^{1}$, Fiorenza Giganti ${ }^{2}$ (D) and Gianluca Ficca ${ }^{1}$ \\ 1 Department of Psychology, University of Campania L. Vanvitelli, Viale Ellittico 31, 81100 Caserta, Italy; \\ mariangela.cerasuolo@gmail.com (M.C.); francesca.conte@unicampania.it (F.C.); \\ benedettaalbinni@gmail.com (B.A.); oreste.derosa@unicampania.it (O.D.R.); \\ marissalynn.rescott@unicampania.it (M.L.R.); gianluca.ficca@unicampania.it (G.F.) \\ 2 Department NEUROFARBA, University of Firenze, Via di San Salvi 12, 50135 Firenze, Italy; \\ fiorenza.giganti@unifi.it \\ * Correspondence: serena.malloggi@unifi.it; Tel.: +39-055-275-5055 \\ + These authors contributed equally to this work.
}

Citation: Cerasuolo, M.; Malloggi, S.; Conte, F.; Albinni, B.; De Rosa, O.; Rescott, M.L.; Giganti, F.; Ficca, G. The Effects of the COVID19-Related Lockdown Are Modulated by Age: An Italian Study in Toddlers and Pre-Schoolers. Brain Sci. 2021, 11, 1051. https://doi.org/10.3390/ brainsci11081051

Academic Editors: Maurizio Gorgoni, Serena Scarpelli and

Valentina Alfonsi

Received: 18 June 2021

Accepted: 5 August 2021

Published: 9 August 2021

Publisher's Note: MDPI stays neutral with regard to jurisdictional claims in published maps and institutional affiliations.

Copyright: (c) 2021 by the authors. Licensee MDPI, Basel, Switzerland. This article is an open access article distributed under the terms and conditions of the Creative Commons Attribution (CC BY) license (https:// creativecommons.org/licenses/by/ $4.0 /)$

\begin{abstract}
Although the issue has been repeatedly explored, data on the impact of the COVID-19 pandemic on children's sleep quality are inconsistent. To clarify these discrepancies, here we investigate possible age-related differences. During the lockdown, 112 parents of toddlers ( $0-3$ years, $\mathrm{N}=61$ ) and pre-schoolers ( $4-5$ years, $n=51$ ) completed an online survey including the Children's Sleep Habits Questionnaire (CSHQ). Sleep-related items required an additional retrospective judgment, referring to the pre-pandemic period. During the lockdown, sleep schedules were delayed in both age groups whereas sleep quality (CSHQ total scores) improved in pre-schoolers but not in toddlers. Between-groups comparisons revealed that, prior to the lockdown, pre-schoolers showed worse sleep quality than toddlers, whereas this difference disappeared during home confinement. Also, pre-schoolers' sleep timing was advanced before the lockdown and delayed during the lockdown relative to toddlers'. Our data highlight a significant modulation of age on the impact of the pandemic crisis on sleep, with pre-schoolers experiencing greater effects than toddlers. This profile suggests that factors affecting sleep features have different weights at different ages: sleep patterns would be mainly determined by developmental factors (i.e., biological drive) in younger children, whereas environmental factors (e.g., major lifestyle changes) would have a stronger effect on older ones.
\end{abstract}

Keywords: COVID-19 pandemic; children's sleep schedules; children's sleep quality

\section{Introduction}

Italy was the first European country to fight against the COVID-19 infection, with the first outbreaks in the North of the country occurring at the end of February 2020. Within a few days, the contagion rapidly spread across the country. To contain the infection, the Italian Government imposed a nationwide lockdown, lasting from 9 March-18 May 2020. During this period, a range of severe disease control strategies were undertaken, such as home confinement, movement restrictions, smart remote working, and temporary closure of non-essential businesses and schools of every order and degree. Individuals were allowed to leave their homes only for demonstrated necessities, such as health reasons, basic needs, and work. Even though these measures proved useful in preventing further spread of the infection and reducing the overload in intensive care units, this prolonged home confinement had a remarkable impact on people's mental health [1], that may persist in the long-term [2]. In fact, the pandemic emergency represents a complex, unprecedented, psychosocial stressor and the strategies adopted to prevent the contagion have resulted in high rates of anxiety, depression, fear, and panic symptoms [3-5]. The lockdown has also markedly disrupted daily social routines and reduced sunlight exposure, with 
significant consequences on sleep and circadian rhythms. In fact, studies from different countries have shown significant delays in bed- and rise times [6-8], worsened sleep quality [7-10] and increases in insomnia symptoms and sleep disorders [3,4] in adults during the national lockdowns.

Recently, greater attention has been paid to the effects of the pandemic on pre-school and school-aged children, since the abrupt changes in their daily schedules and sleep-wake patterns, due to extended school closure and social isolation, might represent a risk for both physical and psychological well-being [11]. Studies conducted in several countries during the lockdowns showed that, according to parental report, children's bed- and rise times were significantly delayed [12-16] and sleep duration was increased [12,13,17,18].

However, findings regarding the impact of pandemic-related restrictions on children's sleep quality are still inconsistent. On one hand, some studies found a worsening of parentreported sleep quality, as indexed by a sleep disturbances score (in 2-years old toddlers [17], in children aged 6-10 years [15], in children aged 1-12 years old but not in adolescents [16]) and by single Likert-scale items on children's general sleep quality (in children aged 1-5 years, [18]), bedtime resistance, and freshness at awakening [19]. Another interesting study [20] showed that the worsening of sleep quality in children occurred in the initial, acute phase of the pandemic (April 2020) but disappeared at a two-months follow up.

On the other hand, other studies found either no change during the pandemic (i.e., no increase of sleep disturbances in children aged 2-5 years [14]) or even an improvement of sleep quality (in 4-6 years old pre-schoolers [13]), assessed through the Children's Sleep Habits Questionnaire (CSHQ, [21]). Zreik et al. [10] also found that most mothers of their sample reported no changes in their children's sleep quality during home confinement nor any perception of their children's sleep as being problematic.

In sum, extant literature clearly points to changes in children's sleep/wake schedules brought about by the pandemic and related restrictions. Instead, its impact on sleep quality in this population is still poorly understood, possibly due to the age-ranges differences across studies and to the different measures adopted. Therefore, here we aim to investigate whether the pandemic and related lockdown could have differently affected sleep habits and quality according to children's age, namely in toddlers ( $0-3$ years old) and pre-school children (4-5 years old), considering that, during the first years of life, sleep undergoes important quantitative, qualitative and organizational changes [22-25]. To this aim, we adopted for both age-groups the same parent-report instrument, the Children's Sleep Habits Questionnaire (CSHQ, [21]), which allows a detailed assessment of a broad range of sleep dimensions. In addition, we assess parents' sleep quality and their associations with children's sleep, in order to better understand this relationship and replicate previous findings on this topic $[10,14,15]$.

\section{Materials and Methods}

\subsection{Participants and Procedure}

An anonymous online survey was administered to Italian parents/caregivers of preschool children during the Italian lockdown period (from 29 April to 26 May 2020) through the Google Form platform. Considering the unpredictability of changes in restrictive measures (i.e., interruption of the total lockdown), a convenience sample was recruited (through advertisements on research-related websites and social media groups) in order to obtain a sufficient sample size as fast as possible. There was no monetary or credit compensation for participating in the study. The only inclusion criterion was having children aged between 0 and 5 years. A total of 112 parents (mothers $=100$; mean age $=36.84 \pm 7.26$ ) completed the survey and were included in data analysis.

After providing informed consent, participants responded to a set of general sociodemographic questions about themselves (e.g., age, gender, education, region of residence, employment, child and other relative's management) and their children (age, gender) as well as to a few ad-hoc questions related to the COVID-19 emergency. These were followed by a set of standardized questionnaires, i.e., the Pittsburgh Sleep Quality Index 
(PSQI, [26]) and the Children's Sleep Habits Questionnaire (CSHQ, [21]), to assess parents and children's sleep quality, respectively, and the Perceived Stress Scale (PSS-10, [27]), to assess parent's perception of stress. Importantly, all items regarding sleep required the participant to report both on their current situation and, retrospectively, on the month preceding the lockdown.

The survey took about 15-20 min to be completed. The study protocol was approved by the ethical committee of the University of Campania "L. Vanvitelli" (code: 14/2020) and was conducted in accordance with the Declaration of Helsinki.

\subsection{The Survey}

In the first section of the survey, we assessed parents' perceptions of the COVID-19 emergency, as well as the consequent changes in their daily lives. Participants were asked whether they knew someone who was positive for COVID-19 or deceased because of it, whether their working condition had changed during the lockdown (i.e., "working from home/remote working", "stopped working"), to what extent their lifestyle was affected (i.e., "not at all", "a little", "somewhat", "much"), how their activity level had changed (i.e., "more sedentary", "as usual", "more active"), how afraid they felt (i.e., "not at all", "moderately", "extremely"), and an evaluation of their mood (on a 5-point scale from "extremely positive" to "extremely negative").

Parents' stress level was measured through the 10-item version of the Perceived Stress Scale (PSS-10 [27]), which assesses "how unpredictable, uncontrollable, and overloaded" respondents find their lives. Total scores range from 0 to 40 , with higher scores indicating higher levels of perceived stress [27].

Parents' sleep quality was assessed through the PSQI [26]. In order to obtain retrospective assessments, all items of this questionnaire required two answers: one referring to the current situation and one to the participant's situation before the lockdown. The PSQI cut-off score was used to discriminate "good" from "poor" sleepers (scores $>5$ indicate poor sleep quality, [28]). Habitual bedtimes (hh:mm) and rise times (hh:mm) were also obtained from the two corresponding items of the PSQI.

Children's sleep was assessed through the Children's Sleep Habits Questionnaire (CSHQ, [21]). The CSHQ is a parent-report questionnaire, widely used to examine sleep behaviour and habits in pre-school [29] and school-aged children [30]. Recently, the CSHQ has also been employed in a few studies to assess sleep characteristics in infants [31,32]. In order to obtain retrospective assessments, parents were asked to respond to each item of the questionnaire both by referring to their children's current situation and to their situation before the lockdown. The questionnaire provides a total score (CSHQ total score) as well as scores to eight subscales: (1) Bedtime Resistance (BR), (2) Sleep Onset Delay (SOD), (3) Sleep Duration (SD), (4) Sleep Anxiety (SA), (5) Night Waking (NW), (6) Parasomnias (P), (7) Sleep Disordered Breathing (SDB), and (8) Daytime Sleepiness (DS). Items are rated on a 3-point scale ranging from "usually" (five to seven times/week) to "sometimes" (two to four times/week) to "rarely" (zero times to one time/week), with higher scores indicating more disturbed sleep. A total score of 41 has been reported to be a sensitive clinical cut-off for the identification of probable sleep problems [21]. The questionnaire also includes items regarding bed- and rise times during both weekdays and weekends.

\subsection{Data Analysis}

Statistical analyses were performed using the SPSS statistics software (version 27.0, IBM Corp., Armonk, NY, USA). Due to the non-normal distribution of variables (as assessed through the Shapiro-Wilk test), non-parametric statistics was chosen for the data analysis.

A chi-square test was conducted to check that parents of toddlers ( $0-3$ years) did not differ from those of pre-schoolers (4-5 years) in terms of gender, education, working status, lifestyle changes and variables related to the COVID-19 emergency. The same test was used to evaluate differences between toddlers and pre-schoolers in gender distribution. 
Changes in parental sleep quality (PSQI total score) and habits (habitual bed and rise times) that occurred during the lockdown relative to the pre-pandemic period were assessed through Wilcoxon's signed rank test. The same test was used to compare current and retrospective assessments of children's sleep (CSHQ total score and sub-scores; bedand rise times; frequency of naps). Data on children's bed- and rise times have been extracted from the CSHQ and separately analyzed for weekdays and weekends, in light of previous literature showing weekday-to-weekend sleep/wake rhythm discrepancies in children [33-35]. The abovementioned analyses were conducted separately for the two age groups.

Differences between the two age groups in age (both parents' and children's), PSQI and CSHQ scores, as well as in sleep schedules, were analyzed by means of Mann-Whitney test, separately for current and retrospective assessments. Relationships between sleep quality (both parents' and children's), parents' stress, lifestyle changes, mood and fear during the lockdown were investigated through Spearman's analysis of correlation.

Following statistical guidelines to correct for multiple testing without running a too high risk of Type II Error (see, for example, [36]), we applied an adapted Bonferroni procedure (as in $[37,38])$. The conventional alpha value $(p \leq 0.05)$ was divided by two, that is the number of relevant sleep "dimensions" addressed in our research ("sleep schedules" and "sleep quality"). Therefore, significance was set at $p \leq 0.025$.

\section{Results}

\subsection{Demographics}

Sixty-one respondents ( $54.4 \%$ of the sample) reported having a child aged 0 to 3 years, while the remaining 51 participants (45.5\% of the sample) had a child aged between 4 and 5 . Demographic information about the sample is shown in Table 1.

Table 1. Demographic characteristics of the sample and their differences between groups.

\begin{tabular}{cccccc}
\hline & $\boldsymbol{n}$ & Parents' Age & Parents' Gender & Children's Age & Children's Gender \\
\hline Toddlers & 61 & $34.84 \pm 5.21$ & $7 \mathrm{M}, 54 \mathrm{~F}$ & $1.69 \pm 0.98$ & $44 \mathrm{M}, 17 \mathrm{~F}$ \\
Pre-schoolers & 51 & $39.24 \pm 8.58$ & $5 \mathrm{M}, 46 \mathrm{~F}$ & $4.75 \pm 1.23$ & $22 \mathrm{M}, 29 \mathrm{~F}$ \\
tot & 112 & $36.85 \pm 7.26$ & $12 \mathrm{M}, 100 \mathrm{~F}$ & $3.09 \pm 1.88$ & $66 \mathrm{M}, 46 \mathrm{~F}$ \\
& & $\mathrm{U}=2043.00$ & $\chi^{2}=0.81$ & $\mathrm{U}=3111.00$ & $\chi^{2}=9.65$ \\
& & $p=0.004$ & ns & $p<0.001$ & $p=0.002$ \\
\hline
\end{tabular}

\subsection{General Information and COVID-19 Items}

Table 2 shows the distribution of the sample on general information items as well as COVID-19 items, separately for toddlers' and pre-schoolers' parents. The chi-squared test showed that the two groups of parents did not differ on any of the items.

Table 2. Statistics of respondents related to general information and COVID-19 items. All values are expressed in \%.

\begin{tabular}{|c|c|c|c|c|}
\hline \multicolumn{2}{|c|}{ General Information } & Parents of Toddlers & Parents of Pre-Schoolers & Chi-Squared Test \\
\hline \multirow{4}{*}{ Education level } & Junior High School & $6.6 \%$ & $7.8 \%$ & \multirow{4}{*}{$\chi^{2}=7.41, \mathrm{~ns}$} \\
\hline & High school & $23.0 \%$ & $45.1 \%$ & \\
\hline & Graduation & $42.6 \%$ & $33.3 \%$ & \\
\hline & Post graduation & $27.9 \%$ & $13.7 \%$ & \\
\hline \multirow{4}{*}{ Profession } & Employed & $54.1 \%$ & $52.9 \%$ & \multirow{4}{*}{$\chi^{2}=3.15, \mathrm{~ns}$} \\
\hline & Self-employed & $29.5 \%$ & $21.6 \%$ & \\
\hline & Student & $1.6 \%$ & $0.0 \%$ & \\
\hline & Unemployed & $14.8 \%$ & $25.5 \%$ & \\
\hline \multirow{3}{*}{ Work continuation } & Yes & $23.0 \%$ & $15.1 \%$ & \multirow{3}{*}{$\chi^{2}=3.04, \mathrm{~ns}$} \\
\hline & No & $44.3 \%$ & $60.8 \%$ & \\
\hline & From home & $32.8 \%$ & $23.5 \%$ & \\
\hline \multirow{2}{*}{$\begin{array}{l}\text { Helps in the management } \\
\text { of children }\end{array}$} & Yes & $85.2 \%$ & $82.4 \%$ & \multirow{2}{*}{$\chi^{2}=0.17, \mathrm{~ns}$} \\
\hline & No & $14.8 \%$ & $16.6 \%$ & \\
\hline
\end{tabular}


Table 2. Cont.

\begin{tabular}{|c|c|c|c|c|}
\hline \multicolumn{2}{|c|}{ General Information } & Parents of Toddlers & Parents of Pre-Schoolers & Chi-Squared Test \\
\hline \multicolumn{5}{|c|}{ COVID-19 items } \\
\hline \multirow{3}{*}{ How is your current lifestyle? } & More sedentary & $72.1 \%$ & $66.70 \%$ & \multirow{3}{*}{$\chi^{2}=3.53, \mathrm{~ns}$} \\
\hline & As usual & $21.3 \%$ & $15.70 \%$ & \\
\hline & More active & $6.6 \%$ & $17.60 \%$ & \\
\hline \multirow{4}{*}{$\begin{array}{l}\text { How much has your } \\
\text { lifestyle changed? }\end{array}$} & At all & $1.6 \%$ & $0 \%$ & \multirow{4}{*}{$\chi^{2}=2.87 . \mathrm{ns}$} \\
\hline & A little & $16.4 \%$ & $7.80 \%$ & \\
\hline & Moderately & $36.1 \%$ & $43.10 \%$ & \\
\hline & Extremely & $45.9 \%$ & $49.00 \%$ & \\
\hline \multirow{2}{*}{$\begin{array}{c}\text { Do you know someone who } \\
\text { has resulted positive to } \\
\text { COVID-19? }\end{array}$} & Yes & $32.8 \%$ & $39.20 \%$ & \multirow{2}{*}{$\chi^{2}=0.50, \mathrm{~ns}$} \\
\hline & No & $67.2 \%$ & $60.80 \%$ & \\
\hline \multirow{2}{*}{$\begin{array}{c}\text { Do you know someone who } \\
\text { has deceased because of } \\
\text { COVID-19? }\end{array}$} & Yes & $11.5 \%$ & $23.50 \%$ & \multirow{2}{*}{$\chi^{2}=2.86, \mathrm{~ns}$} \\
\hline & No & $88.50 \%$ & $76.50 \%$ & \\
\hline \multirow{5}{*}{$\begin{array}{l}\text { How is your mood } \\
\text { in general? }\end{array}$} & Very positive & $3.30 \%$ & $2.00 \%$ & \multirow{5}{*}{$\chi^{2}=1.49, \mathrm{~ns}$} \\
\hline & Moderately positive & $27.90 \%$ & $35.30 \%$ & \\
\hline & Neutral & $41.00 \%$ & $31.40 \%$ & \\
\hline & Moderately negative & $26.20 \%$ & $29.40 \%$ & \\
\hline & Very negative & $1.60 \%$ & $2.00 \%$ & \\
\hline \multirow{3}{*}{ How scared do you feel? } & At all & $9.80 \%$ & $3.90 \%$ & \multirow{3}{*}{$\chi^{2}=1.46, \mathrm{~ns}$} \\
\hline & Moderately & $72.10 \%$ & $76.50 \%$ & \\
\hline & Extremely & $18.80 \%$ & $19.60 \%$ & \\
\hline
\end{tabular}

\subsection{Differences in Children's Sleep Schedules across Time Points and Age Groups}

Figure 1 displays bed- and rise times (on weekdays and weekends) before and during the lockdown in toddlers and pre-schoolers.

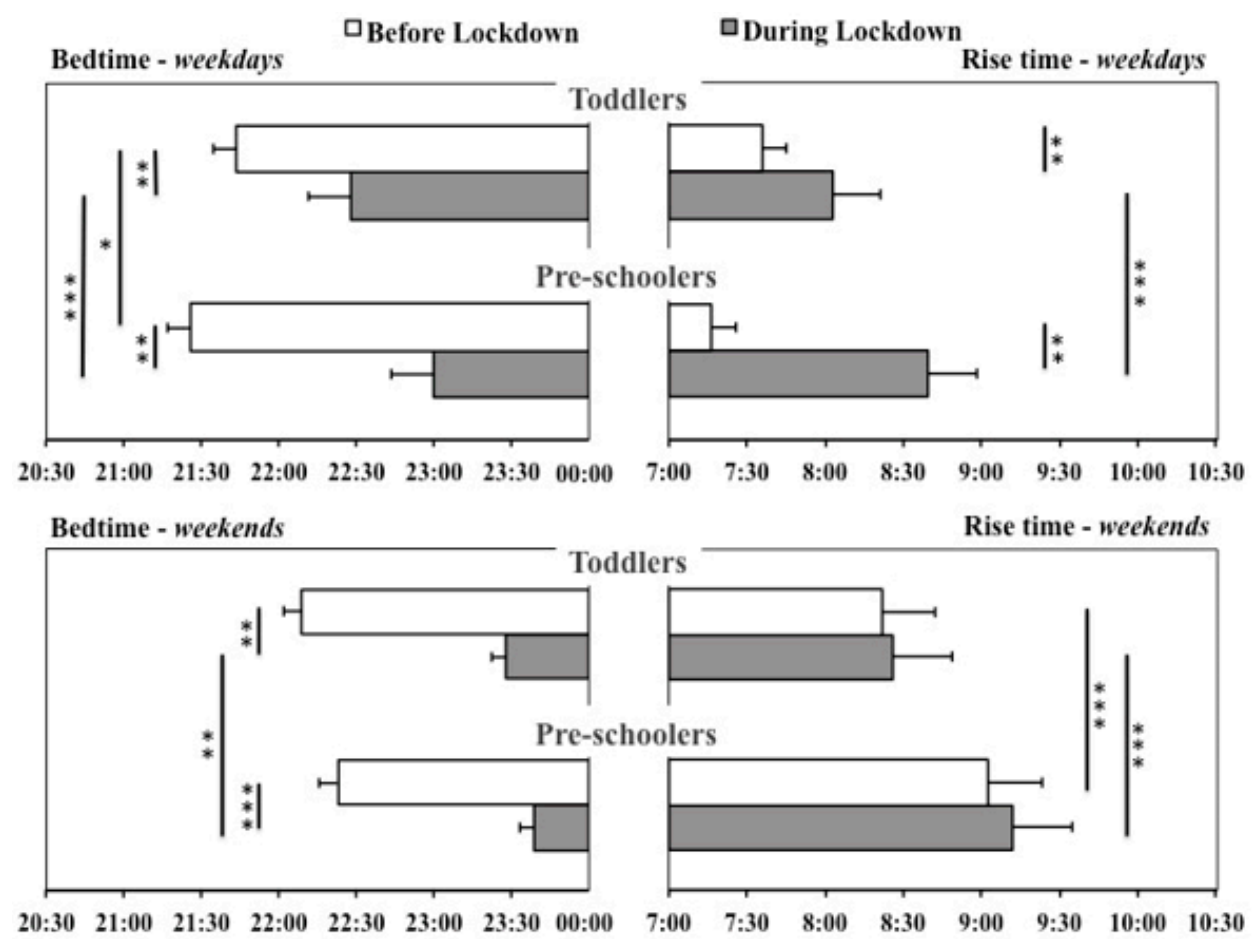

Figure 1. Bed- and rise times on weekdays and weekends in toddlers and pre-schoolers before and during the lockdown. Error bars represent standard error of the mean. Significant within-groups and between-groups comparisons are reported. ${ }^{*} p<0.025 ;{ }^{* *} p<0.01 ;{ }^{* * *} p<0.001$. 
On weekdays, bed- and rise times were significantly delayed during the lockdown (compared to the pre-pandemic period) in both age groups (all four $p^{\prime} \mathrm{s}<0.003$ ). This lockdown-related delay was more pronounced in pre-schoolers, as indexed by the fact that, relative to toddlers, their bedtimes were earlier before the lockdown $(p=0.020)$ and both their bed- and rise times were later during the lockdown (both $p^{\prime} s<0.001$ ).

As for weekends, bedtimes were delayed in both toddlers $(p=0.008)$ and pre-schoolers $(p<0.001)$ during the lockdown relative to before, whereas rise times were unchanged in both groups. Between-groups comparisons revealed that, before the lockdown, bedtimes did not differ between groups, whereas pre-schoolers went to bed significantly later during the lockdown $(p=0.008)$. Pre-schoolers also displayed later weekend rise times both before and during the lockdown (both $p^{\prime} \mathrm{s}<0.001$ ).

Napping frequency increased during the lockdown in both toddlers $(p=0.004)$ and pre-schoolers $(p=0.01)$. Between-groups comparisons revealed that pre-schoolers napped more frequently than toddlers both before and during the lockdown (both $p^{\prime} s<0.001$ ).

\subsection{Differences in Children's Sleep Quality across Time Points and Age Groups}

Figure 2 displays CSHQ total scores before and during the lockdown in toddlers and pre-schoolers. Scores at the CSHQ subscales are shown in Table 3.

Toddlers and pre-schoolers showed different sleep quality profiles over time. While CSHQ total score was unchanged during the lockdown in toddlers, it was decreased in pre-schoolers (indicating improved sleep quality, $p=0.020$ ). Accordingly, pre-schoolers showed significantly decreased scores at all the CSHQ subscales (all $\left.p^{\prime} \mathrm{s}<0.025\right)$ except the Sleep Onset Delay and Sleep Disordered Breathing subscales, which were unchanged, and the Daytime Sleepiness subscale, which, instead, showed increased scores $(p<0.001)$. In toddlers, CSHQ scores were decreased only at the Bedtime Resistance, Sleep Onset Delay, Night Waking and Parasomnias subscales (all $p^{\prime} s<0.01$ ), whereas the Daytime Sleepiness subscale showed increased scores $(p<0.001)$.

As for comparisons between toddlers and pre-schoolers, during the pre-pandemic period the two groups differed in several CSHQ indices. In fact, relative to toddlers, pre-schoolers displayed higher CSHQ total scores $(p=0.022)$, i.e., lower sleep quality, as well as higher scores at several subscales (Bedtime Resistance, Sleep Duration and Night Awakenings, all $\left.p^{\prime} \mathrm{s}<0.025\right)$. Only the Daytime Sleepiness subscale showed the opposite trend, with toddlers scoring significantly higher $(p=0.001)$. Interestingly, all differences between groups (including both the CSHQ total score and its sub-scores) disappeared during the lockdown.

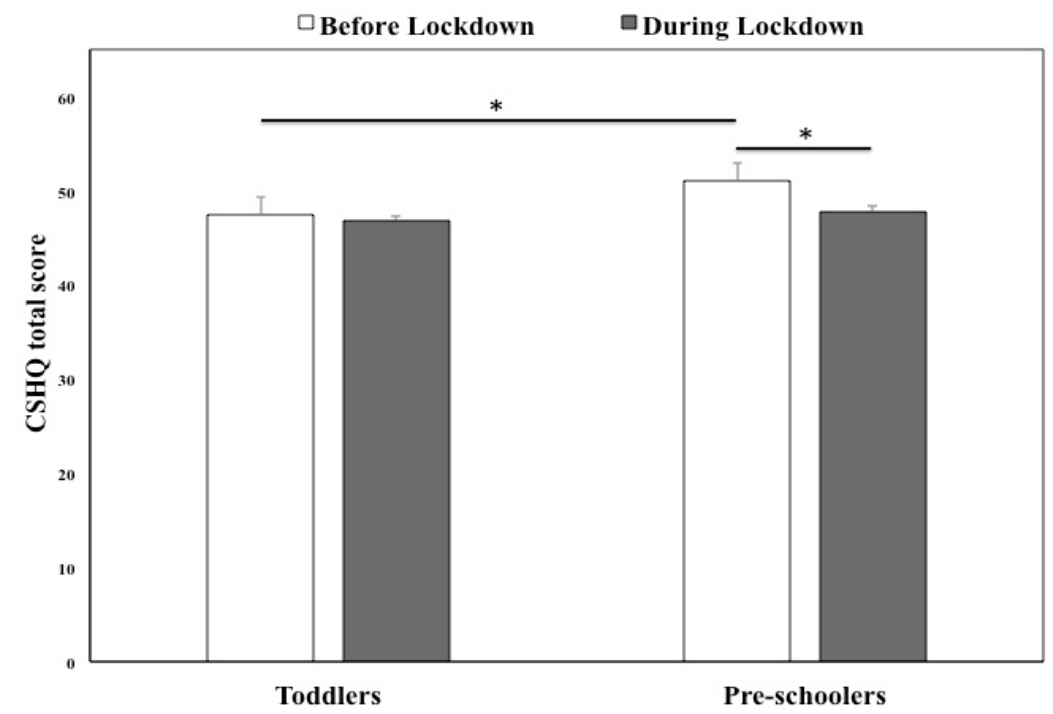

Figure 2. CSHQ total scores of toddlers and pre-schoolers before and during the lockdown. Error bars represent standard error of the mean. Significant within-groups and between-groups comparisons are reported. ${ }^{*} p<0.025$. 
Table 3. CSHQ total score and sub-scores before and during the lockdown in toddlers and pre-schoolers.

\begin{tabular}{cccc}
\hline & & Pre-Lockdown & Lockdown \\
\hline \multirow{2}{*}{ CSHQ total score } & toddlers & $47.51 \pm 8.26$ & $46.82 \pm 8.10$ \\
& pre-schoolers & $51.12 \pm 6.36$ & $47.82 \pm 8.08$ \\
Bedtime Resistance & toddlers & $6.26 \pm 2.59$ & $5.70 \pm 2.75$ \\
& pre-schoolers & $8.63 \pm 2.50$ & $6.73 \pm 2.91$ \\
Sleep Onset Delay & toddlers & $1.52 \pm 0.54$ & $1.23 \pm 0.78$ \\
& pre-schoolers & $1.63 \pm 0.69$ & $1.37 \pm 0.80$ \\
Sleep Duration & toddlers & $4.74 \pm 1.55$ & $4.56 \pm 1.66$ \\
& pre-schoolers & $5.31 \pm 1.09$ & $4.53 \pm 1.81$ \\
Sleep Anxiety & toddlers & $4.52 \pm 2.05$ & $4.57 \pm 1.66$ \\
& pre-schoolers & $5.31 \pm 2.26$ & $4.49 \pm 2.33$ \\
Night Waking & toddlers & $3.80 \pm 1.71$ & $3.43 \pm 1.82$ \\
& pre-schoolers & $4.55 \pm 1.54$ & $3.69 \pm 1.86$ \\
Parasomnias & toddlers & $12.07 \pm 1.50$ & $11.59 \pm 1.72$ \\
Sleep Disordered & pre-schoolers & $12.37 \pm 1.31$ & $11.53 \pm 1.86$ \\
Breathing & toddlers & $5.59 \pm 0.67$ & $5.57 \pm 0.69$ \\
Daytime Sleepiness & pre-schoolers & $5.78 \pm 0.50$ & $5.71 \pm 0.64$ \\
& toddlers & $9.00 \pm 2.82$ & $10.16 \pm 1.58$ \\
& pre-schoolers & $7.53 \pm 2.53$ & $9.78 \pm 2.02$ \\
\hline
\end{tabular}

\subsection{Changes in Parents' Sleep during the Lockdown}

Adults' sleep timing was markedly affected by the lockdown, with parents of both toddlers and pre-schoolers reporting significantly delayed bed-and rise times relative to before the lockdown (all four $p^{\prime} s<0.001$ ). Both groups of parents also displayed worsened sleep quality, as indexed by the significant increase of PSQI total scores from the prepandemic period to the lockdown (toddlers' parents: $p=0.016$; pre-schoolers' parents: $p<0.001)$. Of note, during the lockdown average PSQI scores were raised beyond the cut-off for "poor" sleepers in both groups.

No differences in sleep timing or quality emerged between toddlers' and pre-schoolers' parents either before or during the lockdown. Parents' sleep schedules and sleep quality before and during the lockdown are displayed in Table 4 (separately for toddlers' and pre-schoolers' parents).

Table 4. Sleep schedules and sleep quality before and during the lockdown in toddlers' and preschoolers' parents.

\begin{tabular}{cccc}
\hline & & Pre-Lockdown & Lockdown \\
\hline \multirow{2}{*}{ Bedtime (hh:mm) } & toddlers' parents & $22: 39 \pm 01: 02$ & $23: 21 \pm 01: 09$ \\
& pre-schoolers' parents & $22: 18 \pm 00: 58$ & $23: 33 \pm 01: 24$ \\
Rise time (hh:mm) & toddlers' parents & $07: 20 \pm 0: 44$ & $07: 58 \pm 0: 43$ \\
& pre-schoolers' parents & $07: 05 \pm 0: 41$ & $08: 14 \pm 01: 13$ \\
\multirow{2}{*}{ PSQI total score } & toddlers' parents & $4.26 \pm 1.83$ & $5.45 \pm 3.33$ \\
& pre-schoolers' parents & $4.02 \pm 2.12$ & $6.06 \pm 3.39$ \\
\hline
\end{tabular}

3.6. Relationships between Children's Sleep Features and Parents' Sleep, Behavioural and Psychological Measures during the Lockdown

Correlations among sleep, behavioural (lifestyle changes) and psychological variables (stress, mood, fear) in the total sample are reported in Table 5.

A significant negative correlation emerged between parents' and children's sleep quality measures (PSQI and CSHQ total scores, respectively), indicating that higher sleep quality in children was associated to lower sleep quality in parents and vice versa.

Furthermore, parent's PSQI total scores during the lockdown were found to positively correlate with PSS-10 scores and item scores on mood and fear, with worse sleep quality corresponding to higher stress, lower mood and higher fear. Instead, children's sleep quality (CSHQ total score) showed opposite associations with these variables. 
Table 5. Spearman's correlation between sleep, behavioural and psychological variables during the lockdown in the total sample. ${ }^{*} p \leq 0.01 ;{ }^{* *} p \leq 0.001$.

\begin{tabular}{lcccccc}
\hline & $\mathbf{1}$ & $\mathbf{2}$ & $\mathbf{3}$ & $\mathbf{4}$ & $\mathbf{5}$ & $\mathbf{6}$ \\
\hline 1. PSQI & - & & & & & \\
2. CSHQ & $-0.433^{* *}$ & - & & & & \\
3. PSS-10 & $0.597^{* *}$ & $-0.422^{* *}$ & - & & & \\
4. Lifestyle & 0.188 & -0.210 & $0.306^{*}$ & - & - & \\
change & $0.392^{* *}$ & $-0.248^{*}$ & $0.490^{* *}$ & 0.161 & - & \\
5. Mood & $0.277^{*}$ & $-0.252^{*}$ & $0.342^{*}$ & $0.263^{*}$ & $0.358^{* *}$ & - \\
6. Fear & &
\end{tabular}

Notes. PSQI: higher PSQI scores correspond to lower sleep quality. CSHQ: higher CSHQ scores correspond to lower sleep quality. PSS-10: higher scores indicate higher levels of perceived stress. Lifestyle change: higher scores correspond to more changes in lifestyle. Mood: higher scores reflect a more negative mood. Fear: higher scores indicate higher perceived fear.

\section{Discussion}

This study addresses the impact of the lockdown imposed by the Italian government during the first wave of the COVID-19 pandemic (spring 2020) on children's and their parents' sleep schedules and quality. Specifically, we aimed to investigate children's sleep through the CSHQ, which has not previously been used in Italian COVID-19-related studies, as well as to explore possible differential effects of the pandemic emergency on toddlers (aged 0-3 years) and pre-schoolers (aged $4-5$ years).

Firstly, we observed significant changes in sleep/wake schedules in the overall sample of children, with delayed bed- and rise times in both toddlers and pre-schoolers during home confinement. These findings confirm extant literature showing a phase delay in children [14-16], adolescents [16,39] and adults [6-8] during the COVID-19 pandemic. As for weekday/weekend discrepancies in sleep schedules, which have not been assessed by previous pandemic studies [13-15], we found that the difference in sleep timing between weekdays and weekends was drastically reduced during the lockdown, especially in pre-school children.

Moreover, our findings on parents' sleep schedules and sleep quality confirm, although in a smaller sample, the now ample literature on pandemic-related sleep changes in the adult population. In fact, both toddlers' and pre-schoolers' parents displayed delayed sleep timing (as in, e.g., [6-8]) as well as an impoverishment of sleep quality (as in, e.g., [3,7-9]). Notably, in both groups of parents, average PSQI scores, which did not reach the cut-off for "poor sleepers" in the pre-pandemic period, were raised above it during the lockdown. Also, unsurprisingly, we found that poorer sleep quality during the lockdown was associated with higher perceived stress, worsened mood, and greater fear of contagion in the parents.

As for children's sleep quality, we found a significant decrease, during the lockdown, of CSHQ total scores (indicating improved sleep quality) in pre-schoolers but not in toddlers, whose scores remained stable. Overall, this finding is in line with previous studies showing that children's sleep quality was, on average, less affected than that of adults by the pandemic $[10,14,15]$ or was even improved [13]. Also, it is coherent with Lim et al.'s observation [12] that, in their larger sample of 593 parents (of children aged 3 to 16 years), $50 \%$ perceived an improvement of their child's sleep, $42 \%$ found it unchanged, and only $7 \%$ reported a worsening. Instead, the result is in contrast to other studies reporting a worsening of children's sleep quality during the first wave of the pandemic [15-18,20]. Interestingly, the only other study observing a clear-cut improvement of children's sleep quality was that by Liu et al. [13], who used the same instrument employed in our study (the CSHQ). This observation suggests that the inconsistent results obtained on children's sleep quality during the pandemic may be somehow related to the different instruments used. In fact, besides studies relying on single item assessments [18,19], most studies on the topic [14-17] used the Sleep Disturbance Scale for Children (SDSC, [40]), which specifically targets sleep disorders, whereas the CSHQ addresses a broader range of sleep dimensions. Therefore, it may be hypothesized that, despite a pandemic-related increase 
in children's sleep disturbances (expressed by higher SDSC total scores in the abovementioned studies), their overall sleep quality (assessed through the CSHQ in our study and in [13]) is improved.

We also observed that both groups of children experienced increased napping frequency and sleepiness (indexed by the Daytime Sleepiness subscale of the CSHQ) during the lockdown. These findings are compatible with recent studies showing that the COVID-19 pandemic induced significant changes in the quantity and nature of physical activity in children, with increased sedentary behaviors and use of electronic devices (e.g., [41]), which have been shown to be associated with increased daytime sleepiness in children $[42,43]$. In line with this hypothesis, the increased napping frequency may be consequent to the higher sleepiness, paired with the greater opportunity to sleep during the day. However, since we did not collect data on the timing and duration of naps, nor on the use of electronic devices, specific hypotheses on this set of findings remain speculative.

Our findings also point to age-related differences as a further, complementary, explanation of the discrepant data on children's sleep quality during the pandemic. Indeed, as mentioned above, pre-schoolers and toddlers displayed different patterns of sleep quality changes across the two time points (before and during the lockdown), with no change in toddlers and a significant improvement in pre-schoolers. Our between-groups comparisons revealed that, prior to the lockdown, pre-schoolers showed significantly worse overall sleep quality (higher CSHQ total scores) than toddlers, whereas this difference disappeared during home confinement. The profile observed for sleep quality is coherent with that which emerged from our between-groups comparisons on sleep schedules before and during the lockdown. Indeed, in the pre-pandemic period, pre-schoolers went to bed earlier than toddlers during the week, probably due to their kindergarten schedules. Instead, during the lockdown, we observed an inverted pattern, with pre-schoolers showing later bed-and rise times than toddlers both on weekdays and weekends. Therefore, our overall pattern of findings suggests that the pandemic and related lockdown has affected older children to a greater extent than younger ones. A plausible hypothesis is that daily routines were less affected by the COVID-19 emergency in toddlers compared to pre-schoolers' families. In fact, it is likely that in many cases mothers of the youngest children were already spending most of their time at home (either not working or on maternity leave) when the lockdown was mandated, whereas the households of older children would have undergone greater modifications to every-day schedules. Indeed, the proportion of parents reporting a moderate to extreme degree of lifestyle change with the lockdown was slightly higher in the pre-schoolers than the toddlers group, as was the proportion of parents reporting changes in working status. However, these between-groups differences in lifestyle and working status changes were non-significant. Another hypothesis is that factors affecting sleep features may have different weights at the different ages. In toddlers, sleep characteristics may be mainly determined by developmental factors, accounting for the deep structural and organizational changes of sleep that occur in the first years of life [22-25]. The stronger effect of this internal, biological, drive would explain the greater stability of toddlers' sleep patterns and quality in the face of the major lifestyle changes brought about by the pandemic. In pre-schoolers, instead, the drive of environmental factors would be stronger than that of developmental ones in determining sleep characteristics. This explanation is in line with results from Gruber and colleagues [39], who highlighted the beneficial effects of school closure due to the COVID-19 pandemic on sleep in a sample of adolescents. According to the authors [39], changes in students' daily routines, with distance teaching starting later than usual, allowed a re-alignment of their naturally delayed sleep patterns with externally imposed sleep-wake schedules. In line with this idea, we have previously suggested that school schedules and school-day structure should be reorganized according to children's chronopsychological variations during the day [44].

Finally, a peculiar result emerged from our correlation analysis. We observed a negative correlation between parent's PSQI scores and children's CSHQ total scores, indicating an inverse association between parents' and children's sleep quality. This result is at 
variance with data from two other studies assessing relationships between parents' and children's sleep quality during the pandemic: Cellini et al. [15] did not find any significant association (although note that their study was conducted on children of a different age range, i.e., 6-10 years), whereas Di Giorgio et al. [14] showed, in a similar sample (aged 2-5 years), a positive relationship between mothers' and children's sleep changes, which was mediated by the mothers' working condition. Also, this finding appears counterintuitive, especially in light of previous studies reporting a positive association between sleep quality in mothers and their children [45-47], as well as a negative impact of parents' distress on their own sleep and on that of their children [48-50]. However, as suggested by Liu et al. [13], it is plausible that the increase of stress, fear and negative mood, along with the more flexible parental work schedules, could have negatively impacted parents sleep and also triggered in them more responsive and protective behaviors, which in turn positively affected their children's sleep quality. This explanation is actually supported by the negative correlations we found between CSHQ total scores and parents' psychological measures (stress, mood, fear). Furthermore, it has been suggested that the widespread introduction of smart-working during the lockdown, along with the increased time spent by parents in child-caring, could represent long-term protective factors for young children's sleep [20,51]. Specifically, parents' practices related to their children's sleep, such as controlling pre-bed routines or their use of electronic devices, could have been enhanced during home confinement, with beneficial effects on their children's sleep [20,51]. However, data on these behaviors have not been collected in our study. Future research is required to better clarify the relationships between parents' and children's sleep, highlighting the other possible individual and family factors involved, both in standard conditions and in stressful conditions such as those characterizing the COVID-19 emergency.

A few caveats impose caution in interpreting our results. First, our small sample size and the use of non-probabilistic sampling limit the generalizability of our findings. Indeed, since there was no compensation for participating in the study, the questionnaire might have attracted mostly respondents with sleep problems (although the improvement we observed in children's sleep leads to exclude that this bias affected children's results). Moreover, the majority of respondents were mothers, probably because they are the primary caregivers of children within the age range considered in our study. In the same vein, our two groups of children differed in gender distribution. However, note that gender disparities in the frequency of sleep problems seem to appear only since late adolescence $[33,38,52,53]$.

Another constraint concerns our use of subjective measurements. Specifically, the possibility that results were biased by parents' misperceptions of their children's sleep [10] should be acknowledged, especially since the survey method, compared, e.g., to sleep diaries administered over longer time frames, requires a single, general assessment. A response bias linked to demand characteristics could also have derived from our use of retrospective questions regarding the period preceding the lockdown. Still, this methodological choice is deemed to be sufficiently reliable by some authors [54] and should be considered in light of the unpredictable instantiation of the lockdown, which did not allow for an a priori planning of research procedures. Unsurprisingly, in fact, surveys including retrospective questions on the pre-pandemic period have been repeatedly employed in sleep studies conducted during the pandemic (e.g. $[7,8,55,56])$.

Finally, our adoption of a non-conservative statistical correction in data analysis, described in the methods, should be taken into account in interpreting our data. This choice was made in order to avoid a high risk of incurring in a Type II Error, which could have prevented the detection of specific differences between the age groups [51].

\section{Conclusions}

Overall, our findings allow us to draw two main conclusions: (a) the COVID-19 pandemic, along with the relevant lifestyle changes brought about by the restrictive measures, affected sleep timing at younger ages in as much a remarkable way as in the adult popula- 
tion, in line with what has been observed in previous studies on sleep during the pandemic; (b) moreover, our results add to the existing literature by highlighting that, when it comes to sleep quality, the comparison across age groups reveals important differences: while adults' sleep is dramatically worsened during the lockdown, toddlers' sleep is basically unchanged and pre-schoolers' sleep is even improved. This pattern of results points to an important modulating role of age on the extent to which sleep has suffered from the pandemic. As a research agenda, our findings point to the importance of investigating whether these age-related differences in the sensitivity of sleep to the global emergency would also extend to other kinds of severe stressful events and abrupt lifestyle disruptions, either in the short- or in the long-term.

Furthermore, our findings point to the importance of more carefully considering the instruments used in sleep research on younger populations. In fact, our results on children's sleep quality are in line with those obtained in another study using the same survey instrument [13], whereas they are discrepant from those obtained on similar age groups using a different questionnaire (e.g., [14,17]). Future theoretical and methodological efforts aimed at better understanding strengths and limitations of each instrument are needed for a clearer description of sleep in specific age groups and, all the more, to quantify sleep changes under particularly stressful conditions such as the COVID-19 pandemic.

Author Contributions: All authors contributed in a meaningful way to this manuscript. Conceptualization, M.C., F.C., F.G. and G.F.; formal analysis, M.C. and S.M.; investigation, B.A., O.D.R. and M.L.R.; methodology, F.C., O.D.R., B.A. and G.F.; project administration, F.C. and G.F.; supervision: F.C., F.G. and G.F.; visualization: S.M., F.C. and O.D.R.; writing-original draft: M.C., S.M. and F.C.; writing-review and editing, F.C., M.L.R., F.G. and G.F. All authors have read and agreed to the published version of the manuscript.

Funding: This research received no external funding.

Institutional Review Board Statement: The study was conducted according to the guidelines of the Declaration of Helsinki, and approved by the Ethics Committee of the University of Campania "L. Vanvitelli" (code: 14/2020).

Informed Consent Statement: Informed consent was obtained from all subjects involved in the study.

Data Availability Statement: The data that support the findings of this study are available from the corresponding author upon reasonable request.

Acknowledgments: This study has been partially supported by the "V:ALERE 2019" project of the University of Campania "L. Vanvitelli".

Conflicts of Interest: The authors declare no conflict of interest.

\section{References}

1. Fiorillo, A.; Gorwood, P. The consequences of the COVID-19 pandemic on mental health and implications for clinical practice. Eur. Psychiatry 2020, 63, e32. [CrossRef] [PubMed]

2. Brooks, S.K.; Webster, R.K.; Smith, L.E.; Woodland, L.; Wessely, S.; Greenberg, N.; Rubin, G.J. The psychological impact of quarantine and how to reduce it: Rapid review of the evidence. Lancet 2020, 395, 912-920. [CrossRef]

3. Fu, W.; Wang, C.; Zou, L.; Guo, Y.; Lu, Z.; Yan, S.; Mao, J. Psychological health, sleep quality, and coping styles to stress facing the COVID-19 in Wuhan, China. Transl. Psychiatry 2020, 10, 1-9. [CrossRef] [PubMed]

4. Gualano, M.R.; Lo Moro, G.; Voglino, G.; Bert, F.; Siliquini, R. Effects of Covid-19 Lockdown on Mental Health and Sleep Disturbances in Italy. Int. J. Environ. Res. Public Health 2020, 17, 4779. [CrossRef]

5. Fiorillo, A.; Sampogna, G.; Giallonardo, V.; Del Vecchio, V.; Luciano, M.; Albert, U.; Carmassi, C.; Carrà, G.; Cirulli, F.; Dell'Osso, B.; et al. Effects of the lockdown on the mental health of the general population during the COVID-19 pandemic in Italy: Results from the COMET collaborative network. Eur. Psychiatry 2020, 63, e87. [CrossRef]

6. Wright, K.P.; Linton, S.K.; Withrow, D.; Casiraghi, L.; Lanza, S.M.; de la Iglesia, H.; Vetter, C.; Depner, C.M. Sleep in university students prior to and during COVID-19 Stay-at-Home orders. Curr. Biol. 2020, 30, R797-R798. [CrossRef]

7. Cellini, N.; Canale, N.; Mioni, G.; Costa, S. Changes in sleep pattern, sense of time and digital media use during COVID-19 lockdown in Italy. J. Sleep Res. 2020, 29, e13074. [CrossRef] [PubMed] 
8. Cellini, N.; Conte, F.; De Rosa, O.; Giganti, F.; Malloggi, S.; Reyt, M.; Guillemin, C.; Schmidt, C.; Muto, V.; Ficca, G. Changes in sleep timing and subjective sleep quality during the COVID-19 lockdown in Italy and Belgium: Age, gender and working status as modulating factors. Sleep Med. 2021, 77, 112-119. [CrossRef] [PubMed]

9. Blume, C.; Schmidt, M.H.; Cajochen, C. Effects of the COVID-19 lockdown on human sleep and rest-activity rhythms. Curr. Biol. 2020, 30, R795-R797. [CrossRef]

10. Zreik, G.; Asraf, K.; Haimov, I.; Tikotzky, L. Maternal perceptions of sleep problems among children and mothers during the coronavirus disease 2019 (COVID-19) pandemic in Israel. J. Sleep Res. 2021, 30, e13201. [CrossRef]

11. Brazendale, K.; Beets, M.W.; Weaver, R.G.; Pate, R.R.; Turner-McGrievy, G.M.; Kaczynski, A.T.; Chandler, J.L.; Bohnert, A.; von Hippel, P.T. Understanding differences between summer vs. school obesogenic behaviors of children: The structured days hypothesis. Int. J. Behav. Nutr. Phys. Act. 2017, 14. [CrossRef] [PubMed]

12. Lim, M.T.C.; Ramamurthy, M.B.; Aishworiya, R.; Rajgor, D.D.; Tran, A.P.; Hiriyur, P.; Kunaseelan, S.; Jabri, M.; Goh, D.Y.T. School closure during the coronavirus disease 2019 (COVID-19) pandemic-Impact on children's sleep. Sleep Med. 2021, 78, 108-114. [CrossRef] [PubMed]

13. Liu, Z.; Tang, H.; Jin, Q.; Wang, G.; Yang, Z.; Chen, H.; Yan, H.; Rao, W.; Owens, J. Sleep of preschoolers during the coronavirus disease 2019 (COVID-19) outbreak. J. Sleep Res. 2021, 30. [CrossRef] [PubMed]

14. Di Giorgio, E.; Di Riso, D.; Mioni, G.; Cellini, N. The interplay between mothers' and children behavioral and psychological factors during COVID-19: An Italian study. Eur. Child Adolesc. Psychiatry 2020, 1, 3. [CrossRef] [PubMed]

15. Cellini, N.; Di Giorgio, E.; Mioni, G.; Di Riso, D. Sleep and Psychological Difficulties in Italian School-Age Children During COVID-19 Lockdown. J. Pediatr. Psychol. 2021, 46, 153-167. [CrossRef]

16. Bruni, O.; Malorgio, E.; Doria, M.; Finotti, E.; Spruyt, K.; Melegari, M.G.; Villa, M.P.; Ferri, R. Changes in sleep patterns and disturbances in children and adolescents in Italy during the Covid-19 outbreak. Sleep Med. 2021. [CrossRef]

17. Lecuelle, F.; Leslie, W.; Huguelet, S.; Franco, P.; Putois, B. Did the COVID-19 lockdown really have no impact on young children's sleep? J. Clin. Sleep Med. 2020, 16, 2121. [CrossRef]

18. Aguilar-Farias, N.; Toledo-Vargas, M.; Miranda-Marquez, S.; Cortinez-O'ryan, A.; Cristi-Montero, C.; Rodriguez-Rodriguez, F.; Martino-Fuentealba, P.; Okely, A.D.; Cruz, B.D.P. Sociodemographic predictors of changes in physical activity, screen time, and sleep among toddlers and preschoolers in chile during the covid-19 pandemic. Int. J. Environ. Res. Public Health 2021, 18, 176. [CrossRef]

19. Dellagiulia, A.; Lionetti, F.; Fasolo, M.; Verderame, C.; Sperati, A.; Alessandri, G. Early impact of COVID-19 lockdown on children's sleep: A 4-week longitudinal study. J. Clin. Sleep Med. 2020, 16, 1639-1640. [CrossRef]

20. Markovic, A.; Mühlematter, C.; Beaugrand, M.; Camos, V.; Kurth, S. Severe effects of the COVID-19 confinement on young children's sleep: A longitudinal study identifying risk and protective factors. J. Sleep Res. 2021, e13314. [CrossRef]

21. Owens, J.A.; Spirito, A.; McGuinn, M. The Children's Sleep Habits Questionnaire (CSHQ): Psychometric properties of a survey instrument for school-aged children. Sleep 2000, 23, 1043-1051. [CrossRef]

22. Curzi-Dascalova, L.; Giganti, F.; Salzarulo, P. Neurophysiological basis and behavior of early sleep development. In Sleep in Children: Developmental Changes in Sleep Patterns, 2nd ed.; CRC Press: Boca Raton, FL, USA, 2008; pp. 1-38. ISBN 9781420060812.

23. Giganti, F.; Ficca, G.; Cioni, G.; Salzarulo, P. Spontaneous awakenings in preterm and term infants assessed throughout 24-h video-recordings. Early Hum. Dev. 2006, 82, 435-440. [CrossRef]

24. Ficca, G.; Fagioli, I.; Giganti, F.; Salzarulo, P. Spontaneous awakenings from sleep in the first year of life. Early Hum. Dev. 1999, 55, 219-228. [CrossRef]

25. Ficca, G.; Fagioli, I.; Salzarulo, P. Sleep organization in the first year of life: Developmental trends in the quiet sleep-paradoxical sleep cycle. J. Sleep Res. 2000, 9, 1-4. [CrossRef] [PubMed]

26. Curcio, G.; Tempesta, D.; Scarlata, S.; Marzano, C.; Moroni, F.; Rossini, P.M.; Ferrara, M.; De Gennaro, L. Validity of the Italian Version of the Pittsburgh Sleep Quality Index (PSQI). Neurol. Sci. 2013, 34, 511-519. [CrossRef] [PubMed]

27. Cohen, S. Perceived stress in a probability sample of the United States-PsycNET. In the Social Psychology of Health: Claremont Symposium on Applied Social Psychology; Spacapan, S., Oskamp, S., Eds.; Sage Publications, Inc.: New York, NY, USA, 1988; pp. 31-67.

28. Buysse, D.J.; Reynolds, C.F.; Monk, T.H.; Berman, S.R.; Kupfer, D.J. The Pittsburgh sleep quality index: A new instrument for psychiatric practice and research. Psychiatry Res. 1989, 28, 193-213. [CrossRef]

29. Goodlin-Jones, B.L.; Sitnick, S.L.; Tang, K.; Liu, J.; Anders, T.F. The Children's Sleep Habits Questionnaire in toddlers and preschool children. J. Dev. Behav. Pediatr. 2008, 29, 82-88. [CrossRef] [PubMed]

30. Owens, J.A.; Spirito, A.; McGuinn, M.; Nobile, C. Sleep habits and sleep disturbance in elementary school-aged children. J. Dev. Behav. Pediatr. 2000, 21, 27-36. [CrossRef]

31. Hairston, I.S.; Waxler, E.; Seng, J.S.; Fezzey, A.G.; Rosenblum, K.L.; Muzik, M. The role of infant sleep in intergenerational transmission of trauma. Sleep 2011, 34, 1373-1383. [CrossRef] [PubMed]

32. Dias, C.C.; Figueiredo, B.; Pinto, T.M. Children's Sleep Habits Questionnaire-Infant Version. J. Pediatr. 2018, 94, 146-154. [CrossRef]

33. Ficca, G.; Conte, F.; De Padova, V.; Zilli, I. Good and Bad Sleep in Childhood: A Questionnaire Survey amongst School Children in Southern Italy. Sleep Disord. 2011, 825981. [CrossRef] 
34. Doi, Y.; Ishihara, K.; Uchiyama, M. Sleep/wake patterns and circadian typology in preschool children based on standardized parental self-reports. Chronobiol. Int. 2014, 31, 328-336. [CrossRef]

35. Sun, W.; Ling, J.; Zhu, X.; Lee, T.M.; Li, S.X. Associations of weekday-to-weekend sleep differences with academic performance and health-related outcomes in school-age children and youths. Sleep Med. Rev. 2019, 46, 27-53. [CrossRef] [PubMed]

36. Benjamini, Y.; Hochberg, Y. Controlling the false discovery rate: A practical and powerful approach to multiple testing. J. R. Stat. Soc. 1995, 57, 289-300. [CrossRef]

37. Arzilli, C.; Cerasuolo, M.; Conte, F.; Bittoni, V.; Gatteschi, C.; Albinni, B.; Giganti, F.; Ficca, G. The Effect of Cognitive Activity on Sleep Maintenance in a Subsequent Daytime Nap. Behav. Sleep Med. 2019, 17, 552-560. [CrossRef]

38. Malloggi, S.; Conte, F.; Gronchi, G.; Ficca, G.; Giganti, F. Prevalence and Determinants of Bad Sleep Perception among Italian Children and Adolescents. Int. J. Environ. Res. Public Health 2020, 17, 9363. [CrossRef]

39. Gruber, R.; Saha, S.; Somerville, G.; Boursier, J.; Wise, M.S. The impact of COVID-19 related school shutdown on sleep in adolescents: A natural experiment. Sleep Med. 2020, 76, 33-35. [CrossRef] [PubMed]

40. Bruni, O.; Ottaviano, S.; Guidetti, V.; Romoli, M.; Innocenzi, M.; Cortesi, F.; Giannotti, F. The Sleep Disturbance Scale for Children (SDSC) construction and validation of an instrument to evaluate sleep disturbances in childhood and adolescence. J. Sleep Res. 1996, 5, 251-261. [CrossRef] [PubMed]

41. Paterson, D.C.; Ramage, K.; Moore, S.A.; Riazi, N.; Tremblay, M.S.; Faulkner, G. Exploring the impact of COVID-19 on the movement behaviors of children and youth: A scoping review of evidence after the first year. J. Sport Health Sci. 2021. [CrossRef] [PubMed]

42. Brunetti, V.C.; O'Loughlin, E.K.; O'Loughlin, J.; Constantin, E.; Pigeon, É. Screen and nonscreen sedentary behavior and sleep in adolescents. Sleep Health 2016, 2, 335-340. [CrossRef] [PubMed]

43. Kang, A.W.; Gans, K.M.; Minkel, J.; Risica, P.M. Correlates of objectively measured sleep and physical activity among Latinx 3-to-5-year old children. J. Pediatr. Nurs. 2021, 60, 40-45. [CrossRef] [PubMed]

44. Cerasuolo, M.; Giganti, F.; Conte, F.; Costanzo, L.M.; della Monica, C.; Arzilli, C.; Marchesano, R.; Perrella, A.; Ficca, G. Schooltime subjective sleepiness and performance in Italian primary school children. Chronobiol. Int. 2016, 33, 883-892. [CrossRef]

45. Meltzer, L.J.; Mindell, J.A. Relationship between child sleep disturbances and maternal sleep, mood, and parenting stress: A pilot study. J. Fam. Psychol. 2007, 21, 67-73. [CrossRef]

46. Mindell, J.A.; Sadeh, A.; Kwon, R.; Goh, D.Y.T. Relationship Between Child and Maternal Sleep: A Developmental and CrossCultural Comparison. J. Pediatr. Psychol. 2015, 40, 689-696. [CrossRef] [PubMed]

47. Urfer-Maurer, N.; Weidmann, R.; Brand, S.; Holsboer-Trachsler, E.; Grob, A.; Weber, P.; Lemola, S. The association of mothers' and fathers' insomnia symptoms with school-aged children's sleep assessed by parent report and in-home sleepelectroencephalography. Sleep Med. 2017, 38, 64-70. [CrossRef] [PubMed]

48. De Stasio, S.; Boldrini, F.; Ragni, B.; Gentile, S. Predictive Factors of Toddlers' Sleep and Parental Stress. Int. J. Environ. Res. Public Health 2020, 17, 2494. [CrossRef] [PubMed]

49. Goldberg, W.A.; Lucas-Thompson, R.G.; Germo, G.R.; Keller, M.A.; Davis, E.P.; Sandman, C.A. Eye of the beholder? Maternal mental health and the quality of infant sleep. Soc. Sci. Med. 2013, 79, 101-108. [CrossRef] [PubMed]

50. McQuillan, M.E.; Bates, J.E.; Staples, A.D.; Deater-Deckard, K. Maternal stress, sleep, and parenting. J. Fam Psychol. 2019, 33, 349-359. [CrossRef]

51. Lionetti, F.; Fasolo, M.; Dellagiulia, A. On the role of moderator on children's sleep health in response to COVID-19. J. Clin. Sleep Med. 2021, 7, 353-354. [CrossRef]

52. Simola, P.; Niskakangas, M.; Liukkonen, K.; Virkkula, P.; Pitkäranta, A.; Kirjavainen, T.; Aronen, E.T. Sleep problems and daytime tiredness in Finnish preschool-aged children-a community survey. Child Care Health Dev. 2010, 36, 805-811. [CrossRef]

53. Russo, P.M.; Bruni, O.; Lucidi, F.; Ferri, R.; Violani, C. Sleep habits and circadian preference in Italian children and adolescents. J. Sleep Res. 2007, 16, 163-169. [CrossRef] [PubMed]

54. Hipp, L.; Bünning, M.; Munnes, S.; Sauermann, A. Problems and pitfalls of retrospective survey questions in COVID-19 studies. Surv. Res. Methods 2020, 14, 109-114.

55. Conte, F.; Rescott, M.L.; De Rosa, O.; Cellini, N.; Coppola, A.; Cerasuolo, M.; Malloggi, S.; Giganti, F.; Ficca, G. Changes in dream features across the first and second waves of the Covid-19 pandemic. J. Sleep Res. 2021, 22, e13425. [CrossRef] [PubMed]

56. Gupta, R.; Grover, S.; Basu, A.; Krishnan, V.; Tripathi, A.; Subramanyam, A.; Nischal, A.; Hussain, A.; Mehra, A.; Ambekar, A.; et al. Changes in sleep pattern and sleep quality during COVID-19 lockdown. Indian J. Psychiatry 2020, 62, 370-378, PMCID:PMC7597722. [CrossRef] [PubMed] 